\title{
Sofrimento mental em vendedores na Grande São Paulo: a destituição do ser pela organização do trabalho
}

\author{
Suffering of sales associates in São Paulo metropolitan area: the \\ destitution of being by work organization
}

\author{
${ }^{1}$ Mestre em Psicologia da Saúde. Psicó- \\ loga da Secretaria Municipal de Saúde \\ e do Centro de Referência em Saúde do \\ Trabalhador de Diadema, SP. \\ Contato: \\ Eliana A. S. Pintor \\ Cerest Diadema \\ Avenida Antonio Piranga, 614 - Centro \\ - Diadema-SP \\ CEP: 09911-000 \\ E-mail: \\ pintoreliana@yahoo.com.br
}

\section{Resumo}

Este trabalho relata a experiência de um serviço de psicologia no atendimento de vendedores com transtornos mentais, discutindo riscos e malefícios causados pela organização do trabalho no ramo de serviços. O sofrimento mental é enfocado a partir da falta de reconhecimento, do conflito família versus trabalho e também pelo conflito ético instalado nos vendedores por uma das empresas focalizadas na pesquisa. São apresentados relatos de oito trabalhadores colhidos por meio do método de entrevistas semiestruturadas e material clínico de sessões de psicoterapia. Todos foram atendidos entre os anos de 2006 e 2009 no Centro de Referência em Saúde do Trabalhador de Diadema, cidade da Grande São Paulo. Os dados revelam como a identidade dos trabalhadores é ameaçada por inúmeras estratégias provocando um vazio existencial que leva ao adoecimento mental. Nesta estrutura, a correlação do lúdico com o trabalho na vida adulta se perde, interrompendo a continuidade do desenvolvimento do ser.

Palavras-chave: saúde mental e trabalho; riscos ocupacionais; ambiente de trabalho; psicanálise; vendedor.

\begin{abstract}
This article reports the experience of a psychology service treating sales associates with mental disorders, and aims at discussing the deleterious effects caused by work organization risk factors within the service sector. Mental suffering is studied focusing on workers' complain of lack of recognition, their conflict between family and work, and on the ethical conflict presented by some employees of one of the companies. Data of eight workers were collected by semi-structured interviews as well as through the clinical material during psychotherapy sessions. All workers received care at the Worker's Health Reference Center, in Diadema, in São Paulo metropolitan area, from 2006 to 2009. Data revealed how workers' identity was threatened by numerous strategies causing an existential vacuum that led to mental ilness. In this structure, the association between ludic and work in adult life was lost, causing a discontinuity of the development process of the being.
\end{abstract}

Keywords: mental health and work; occupational risks; work environment; psychoanalysis; sales associate. 


\section{Introdução}

Estamos habituados a entrar nas lojas e encontrar pessoas prontas para nos atender, sempre solícitas, com um sorriso no rosto, o máximo de gentileza possível e o costumeiro: “Posso ajudar?”. O ambiente de uma loja também nos parece tranquilo, amistoso, ficando agitado apenas em datas especiais, como Natal ou Dia das Mães. Uma realidade de trabalho que em princípio não sugere a existência de sofrimento mental. Porém, este cenário tem sido contrastado com um número crescente de trabalhadores oriundos do comércio que chegam aos Centros de Referência em Saúde do Trabalhador (Cerest) trazendo queixas compatíveis com quadros de depressão, ansiedade, síndrome do pânico e síndrome do esgotamento profissional.

O presente relato tem como objetivo focar a subjetividade dos vendedores em três aspectos da organização do trabalho identificados como cruciais no seu adoecimento: conflito ético, conflito trabalho versus família e reconhecimento. O sofrimento mental será apresentado por meio de vinhetas de oito casos atendidos no Cerest Diadema/SP no período de 2006 a 2009. Deste total de trabalhadores, quatro são funcionários de uma mesma empresa (rede de lojas de varejo - eletrodomésticos, móveis, eletroeletrônicos - de grande porte, com filiais em todo o Brasil), dois de uma empresa de venda de móveis com lojas no Estado de São Paulo e duas do ramo de alimentos (rede de restaurantes de shopping e rede de restaurantes de estrada). Os relatos de casos ajudam a descrever estes ambientes de trabalho e permitem uma aproximação à vivência cotidiana que auxilia na análise da relação entre adoecimento mental e trabalho nesta categoria profissional.

\section{Ser e fazer: necessidades da infância e da vida adulta}

$$
\begin{array}{r}
\text { Após ser, fazer e deixar-se fazer. } \\
\text { Mas ser, antes de tudo. } \\
\text { Winnicott, 1971, p. } 120
\end{array}
$$

Faremos uma aproximação teórica da situação vivenciada pelos vendedores partindo de algumas necessidades que se fazem presentes desde os primórdios de nossa existência e nos acompanham até o entardecer da vida. Abordaremos primeiramente a necessidade de reconhecimento do ser humano. Zimerman (2010) cita um filósofo irlandês - George Berkeley - o qual fez uma articulação entre o "se reconhecer" e o "ser reconhecido”. Segundo o autor, sua afirmação de 1710 que dizia "Ser, é ser percebido" é o equivalente de "Ser, é ser reconhecido". O ser humano, desde os primeiros momentos de vida, necessita do reconhecimento do outro. Winnicott (1971) afirma que a construção de uma segurança básica ou do prazer pela vida se dá através do olhar amoroso da mãe para a criança, a qual espelha para o bebê o encantamento. O bebê olha e é visto e então sente que existe, se sente valorizado. Este espelhamento acontece no decorrer da vida e, de acordo com Zimerman (2010, p. 212):
[...] não é possível conceber qualquer relação humana em que não esteja presente a necessidade de algum tipo de um mútuo reconhecimento.

Traçando um paralelo com o cenário laboral, é fácil perceber que esta necessidade também se fará presente no local de trabalho para haver uma relação saudável.

Em segundo lugar, nos aproximaremos da noção do brincar, no aspecto lúdico da constituição do ser, pois, segundo Safra (2006), no jogo de uma criança, encontra-se a matriz do que serão as suas necessidades fundamentais nas fases da vida adulta e no envelhecimento. Para Winnicott (1971, p. 80):

É no brincar, e somente no brincar, que o individuo criança ou adulto, pode ser criativo e utilizar sua personalidade integral: e é somente sendo criativo que o indivíduo descobre o eu (self).

Desta forma, o trabalho se configura como uma das oportunidades de brincar na vida adulta. Enfocando a atividade de vender, podemos dizer que o modo de vender, as estratégias, o gestual, a voz, enfim, tudo o que compõe o ser está em jogo no momento da ação. O vendedor se dá ao consumidor para realizar a sua tarefa. Safra (2006), ao falar do brincar infantil, esclarece que, ao brincar, a criança institui situações organizadas em termos de espaço e de tempo. A criança, ao brincar, ressignifica o ambiente, transforma a realidade por meio do seu gesto:

Isto significa que todo brincar demanda um tipo de ruptura com o que é dado. O brincar funda mundos, funda a possibilidade de a criança estar no mundo e instituir modos de ser. (SAFRA, 2006, p. 13)

Fazendo a transposição para o mundo do trabalho, evidencia-se a necessidade de haver o espaço para a criatividade, uma margem de liberdade onde possa transitar o imaginário, o lúdico, o ser total do indivíduo e uma forma de organizá-lo que contemple a essência do humano.

Freud escreveu, em 1930, que:

[...] a força motivadora de todas as atividades humanas é um esforço desenvolvido no sentido de duas metas confluentes, a de utilidade e a de obtenção de prazer [...]. (FREUD, 1930, p. 154)

O trabalho nos traz estas duas possibilidades, ou pelo menos deveria trazer. Quando isto acontece, o trabalho se torna um correlato do brincar. O quintal da nossa infância ganha nova dimensão, a qual engloba o trabalho, as artes e outras manifestações culturais.

A tarefa, ao ser constituída, nos constitui e, então, somos aquilo que fazemos. Antunes (1999) afirma que o sentido assumido pelo trabalho que o indivíduo realiza se torna um aspecto muito relevante para a saúde mental, porque tem profunda ligação com a autoimagem e a autoestima, ou seja, com a identidade. Deste modo fica claro que o trabalho assume um papel central na vida do indivíduo, encerrando alguns aspectos vitais para o existir humano: sobrevivência, criatividade, sentimento de pertença e reconhecimento. Estes elementos também constroem o autoconceito, o que confere uma identidade ao sujeito. 
No comércio, geralmente se trabalha para ganhar o valor: piso da categoria profissional acrescido de porcentagem de comissão, nas vendas. O piso é o certo e a comissão, o incerto. Este é um ponto de tensão da atividade dos vendedores. A sobrevivência em uma sociedade capitalista e, por conseguinte, consumista implica que só é aquele que consome. Para se conseguir o patamar mínimo para sobreviver não é possível contentar-se com o piso da categoria. Há que se fazer um esforço para ampliar este ganho. Isto já é explicitado no ato da contratação. Algumas empresas propõem somente a comissão, este é o contrato. Porém, adicione-se a essa tensão, já esperada, metas ou cotas de vendas. Segundo o relato dos trabalhadores, as metas não são fáceis de serem alcançadas e isto incrementa a incerteza, pois, se já é incerto o que se ganha, o não atendimento à expectativa da empresa torna incerta a manutenção do emprego. Um vendedor que não atinge a meta está na lista de corte. O temor de demissão abre caminho para um tipo de ansiedade paranóide: “Quem será a próxima vítima?”. Os gerentes ou encarregados lembram a todo o momento que as metas precisam ser atingidas. Os vendedores contam que os gerentes também são pressionados, o que constrói o efeito dominó, ou seja, forma uma cadeia - a organização do trabalho - contra a qual se sentem impotentes para lutar. Estudo realizado com 39 vendedores de um shopping center em Florianópolis/SC identificou que a ansiedade está muito presente na rotina de trabalho de vendedores. Mais da metade da amostra demonstrou que muito frequentemente ou sempre ficava ansiosa quando não cumpria as metas estipuladas pela organização (MACHADO, 2009).

Se o vendedor não produz o esperado, gera um desapontamento, porque ele é aquilo que produz. Alguns dos vendedores atendidos no Cerest Diadema relatam que não importa se faltou muito pouco para atingir a meta ou se faltou bastante, todos são tratados da mesma maneira, ou seja, aqueles que não conseguem são os incapazes. Isto funciona como uma ameaça permanente à identidade dos trabalhadores, o que gera mais uma incerteza e, agora, no campo da constituição do ser: "Quem eu sou de verdade?"

A pressão para atingir metas também leva a um incremento da competição e por este motivo muitos "colegas" passam a se tratar como rivais. Nesse caso, o suporte afetivo que poderia existir no ambiente de trabalho dentro de uma equipe fica difícil ou muito difícil de acontecer. Apesar de existirem amizades, a forma de organizar o trabalho colabora para a rivalidade, o distanciamento, ataques mútuos devido à sobrecarga, à tensão. Observamos nos relatos dos vendedores afastados que não recebem ligação de amigos do trabalho, apesar de serem funcionários antigos da empresa. Falam de um amigo ou outro. Trata-se de uma forma de desamparo e solidão. Vasques-Menezes, Codo e Medeiros (2000) estudaram a relação entre trabalho e adoecimento mental em professores e demonstraram que a falta de suporte afetivo tem forte influência na exaustão emocional sentida pelos profissionais e provoca, de maneira inconsciente, um endurecimento emocional (despersonalização), tornando-os indiferentes aos problemas do dia a dia e às demandas. Isto significa que esse fator pode contribuir para o desenvolvimento da síndrome do esgotamento profissional.

O cumprimento das cotas de vendas acarreta ainda uma dedicação total ao trabalho. É frequente ouvir destes trabalhadores que não faziam hora de almoço, não desfrutavam de sua folga, viam-se obrigados a fazer hora extra para atingirem a meta estabelecida. Toda esta dedicação ao trabalho cria outro problema: o afastamento da família. O relato destes trabalhadores é carregado de culpa pela pouca atenção dispensada aos filhos e aos cônjuges ou culpa pela impaciência, pelo nervosismo com os familiares, pois já haviam dado o melhor de si mesmos aos clientes e não sobrava nada para a família. O fato de trabalharem aos domingos e feriados impõe um afastamento dos momentos festivos em família (festas de aniversário, churrasco, casamentos). Este é outro aspecto engendrado pela organização do trabalho que colabora grandemente para o surgimento de sofrimento mental e que se constitui num ataque ao autoconceito, à autoestima, modificando aquela identidade já mencionada. Vasques-Menezes e Gazzotti (2000) constataram o mesmo problema em professores e ficou provado que a existência do conflito entre trabalho e família aumenta significativamente a exaustão emocional e a despersonalização, os quais são característicos da síndrome do esgotamento profissional.

Segundo alguns vendedores que nos procuraram no Cerest Diadema, há outro fator que vem elevando a tensão dos vendedores: a venda de garantia do produto e de seguro de vida associados à venda do produto. Segundo uma das vendedoras entrevistadas da rede de lojas de varejo, essa prática foi implantada a partir do ano de 2004. Além da meta de vendas geral, é estabelecida uma meta desses novos produtos. A grande repercussão emocional advinda desta modalidade de venda se dá não só pelo acréscimo de outra meta, mas principalmente pela forma de alcançá-la. Os vendedores dessa rede de lojas de varejo declararam que, como vendem para classes de menor poder aquisitivo, possuem muitos clientes analfabetos ou com baixa escolaridade. Diante disso, a ordem dada pela chefia aos vendedores foi que a garantia e o seguro deviam ser embutidos nas vendas sem que os consumidores soubessem ou consentissem. Nesse momento, a organização do trabalho instalou o conflito ético. Os vendedores contam que, quando esta venda foi implantada, eles explicavam e tentavam convencer o cliente, porém, posteriormente, veio a ordem de embutir. A identidade do trabalhador é aviltada mais uma vez, porque agora ele sente que faz um trabalho sujo, desonesto e, assim, ele se confunde mais uma vez com o produto do seu trabalho.

O ambiente descrito evidencia uma influência nefasta sobre o estado psíquico. Melanie Klein (1932) advertia que uma parte das situações ansiogênicas permanece inacessível à análise e, por isso, pessoas normais ou já analisadas frente a uma situação orgânica ou externa muito desfavorável poderiam sofrer recaídas (SIMON, 1986). Podemos tomar essa afirmação como um alerta sobre a possibilidade de ocorrência de transtornos mentais em toda e qualquer pessoa apesar da boa estrutura emocional. Os riscos pela organização do trabalho podem oferecer esse ambiente muito desfavorável, minando o equilíbrio emocional do indivíduo. 
Winnicott (1971) se refere a indivíduos dominados no lar, prisioneiros em campos de concentração ou vítimas de perseguição política cruel, que, em sua maioria, abandonaram a esperança, deixaram de sofrer e perderam a característica que os tornava humanos, não percebiam o mundo de maneira criativa. Houve a destruição da criatividade pela ação de fatores ambientais, numa data tardia no crescimento pessoal. Os autores demonstram que o sofrimento mental é originado na confluência de uma predisposição atrelada à personalidade com um fator ambiental. No contexto aqui tratado, o fator ambiental é representando pela organização do trabalho, na qual os estudos em saúde mental no trabalho têm encontrado a fonte preponderante dos agravos psíquicos relacionados ao trabalho (SELIGMANN-SILVA, 2003). Esta organização compreende a estrutura hierárquica da empresa, o controle das tarefas, a divisão das atividades, a estrutura temporal do trabalho, as relações interpessoais e intergrupais, que compõem categorias de análise importantes para a compreensão das relações entre trabalho e adoecimento mental (SELIGMANN-SILVA, 2003). Veremos a seguir, por meio dos relatos dos vendedores, como se dá a organização do trabalho no comércio. Os vendedores descrevem um ambiente com vários fatores que se predispõem ao aparecimento de transtornos mentais, transformando o trabalhador em algo destituído de valor, significado, sentimentos, enfim, destituído de uma subjetividade.

\section{Método e material clínico}

O método utilizado foi o de entrevistas semiestruturadas, nas quais colhemos dados de identificação, queixa, os motivos que levaram ao adoecimento mental, ambiente profissional, histórico profissional anterior, história de vida, histórico de saúde (física e emocional), relações afetivas, vida social. Os trabalhadores buscaram espontaneamente o Cerest Diadema almejando fazer a relação de sua doença com o trabalho. As entrevistas foram realizadas pela psicóloga. Quatro deles, após as entrevistas, fizeram acompanhamento psicológico individual no próprio Cerest e, em alguns dos relatos a seguir, foram incluídos fragmentos de material clínico das sessões de psicoterapia. Desses que fizeram psicoterapia, três deles passaram para psicoterapia grupal e uma não concluiu a psicoterapia individual. O material clínico citado a seguir refere-se apenas ao período de atendimento individual. Seis deles foram recebidos no Grupo de Orientação (grupo de recepção de novos usuários realizado pela assistente social ou enfermeira, além de médico do trabalho e auxiliar administrativo) e, depois, encaminhados para consulta psicológica. Duas trabalhadoras chegaram trazidas por trabalhadoras que já estavam em atendimento no serviço e foram encaminhadas diretamente para consulta psicológica. Trata-se de sete mulheres e um homem. Selecionamos trechos de oito entrevistas que trazem referência aos aspectos da organização do trabalho; seis delas foram realizadas com vendedores de grande rede de lojas (quatro de uma mesma empresa - rede de lojas de varejo - com lojas em todo o Brasil, já citada anteriormente, e dois de uma empresa de venda de móveis com várias lojas no Estado de São Paulo); além de uma balconista de rede restaurante de estrada - principais estradas do Estado de São Paulo; e uma garçonete de rede de restaurante de shopping centers presente em várias cidades brasileiras. Todos faziam acompanhamento psiquiátrico (em convênio, rede municipal ou particular) quando chegaram ao Cerest. Os relatos que seguem foram autorizados pelos participantes por meio de termo de consentimento livre e esclarecido. Os trabalhadores receberam nomes fictícios para preservação da identidade, conforme o Quadro 1:

Quadro 1 Características dos pacientes atendidos pelo Cerest-Diadema referidas neste estudo

\begin{tabular}{|c|c|c|c|c|c|}
\hline Nome (fictício) & idade & Profissão & Local de trabalho & Tempo de empresa & Período de atendimento no Cerest \\
\hline Aline & 29 & balconista & Restaurante & 05 anos & Junho/06 a Março/08 \\
\hline Valéria & 42 & vendedora & Loja de movéis & 05 anos & Outubro/06 a Dezembro/06 \\
\hline Lucas & 40 & vendedor & Loja de móveis & 09 anos & Março/07 a Março/08 \\
\hline Marta & 30 & atendente & Restaurante & 03 anos & Março/08 a Maio/08 \\
\hline Sueli & 42 & vendedora & Loja de varejo & 22 anos & Dezembro/08 a Maio/09 \\
\hline Vitória & 46 & vendedora & Loja de varejo & 20 anos & Março/09 a Maio/09 \\
\hline Marina & 34 & vendedora & Loja de varejo & 06 anos & Abril/09 a Maio/09 \\
\hline Raquel & 40 & vendedora & Loja de varejo & 05 anos & Junho/09 a Setembro/09 \\
\hline
\end{tabular}




\section{$O$ ambiente de trabalho e o sofrimento mental nas palavras dos vendedores}

Aline: Apesar de ser balconista no registro da carteira profissional, sua atividade consistia em servir o balcão, lavar utensílios, preparar o pedido do cliente e oferecer outros produtos. O local era muito frequentado pela manhã, devido ao café da manhã, no horário do almoço, final da tarde e nos feriados, pois se tratava de rede de restaurante de Estrada. Havia cobrança por meta de venda (20 mil reais por mês/por cada vendedor) e ameaça de desemprego caso não a atingisse. Aline descreveu um ambiente muito competitivo e relatou que, quando se virava para preparar o café do cliente, vinha outro vendedor oferecer algum salgado e lhe tirava a oportunidade de vender. Os encarregados ganhavam comissões sobre a meta dos vendedores e faziam pressão para vender, além de exigir rapidez no atendimento. Havia palestras para a venda de produtos adicionais (como vender, como servir, como incentivar o cliente a experimentar um produto).

A atividade exigia muita atenção e memória, pois havia código para cada tipo de produto, os quais eram digitados a cada venda; trabalhava em pé e não fazia mais que quinze minutos de horário de almoço. Os sintomas emocionais começaram após quatro anos de trabalho: irritação, insônia, medos (de carros, de andar na rua, de pessoas), isolamento, ouvia vozes (alguém lhe chamando ou uma "zoada na cabeça"), dor no peito e nos ossos. Pouco antes de se afastar, passou a atender os clientes sem cortesia, chorava com facilidade, não conseguia atingir as metas. Fazia horas extras várias vezes. Segundo Aline, não havia participação dos funcionários em nada: “Tudo vem da matriz, nem o gerente dá opinião". Relatou que, quando retornava ao lar, observava que continuava num ritmo acelerado, fazendo tudo correndo e, muitas vezes, não dormia antes das duas da madrugada.

Frases de Aline: "Tinha vontade de ir pra casa correndo pela Imigrantes [Rodovia]. Comecei a ficar com medo de ir sozinha embora, parecia medo de me enfiar no meio dos carros"; "Não consigo ir até lá, nem levo o papel da perícia, fiquei com trauma do lugar" [neste momento começou ter sudorese nas mãos]; "Será que vou voltar a ser como eu era? Nunca fui doente [...]”. Lamentava o extremo nervosismo e a intolerância com os filhos.

Valéria: vendedora de móveis, os seus sintomas começaram após dois anos de trabalho: aflição, zonzeira, não podia ver muita gente. Atribuiu tais sintomas ao trabalho, pois disse sofrer "muita, muita pressão". Além de vender, ela limpava o setor e acompanhava a venda até a entrega ao cliente. Tudo o que acontecesse de errado nesse percurso era da responsabilidade do vendedor. Reclamou de muitos códigos, tinha medo de falhar - trocar algum código. Havia pressão do gerente, do supervisor, da equipe. Geralmente atingia as metas, mas, para isso, trabalhava de domingo a domingo, mesmo não sendo obrigada, e não tinha hora para sair. A loja funcionava em sistema de rodízio; às vezes esperava uma hora para chegar a sua vez de abordar o cliente. Após seis meses de trabalho, mudou-se o supervisor e a pressão por vendas foi intensificada. Relatou que, após um ano e meio de trabalho, começaram alguns sintomas menos graves: irritação, cansaço, esquecimento, perturbação mental e insônia e, mais tarde, adoeceu propriamente.

$\mathrm{Na}$ época que veio ao Cerest, apresentava medo de andar de ônibus, metrô; não andava sozinha e, à noite, tinha sensação de que ia morrer, sonhava muito com o trabalho: "Venda, comissão... É 24 horas no ar".

Passou a se irritar com som (músicas), porque, na loja, o aparelho de som era ligado o dia todo; não queria mais conversar com as pessoas, mesmo em casa.

Lucas: este trabalhador tinha grande identidade com a profissão, relatando que começou a trabalhar aos 13 anos na feira livre, mas sentia que adquiriu um saber que não era valorizado. Já trabalhava com venda de móveis há muitos anos. Quando Lucas foi transferido para a loja de Diadema, essa unidade vendia 150 mil reais/mês. Isso o assustou porque ele já tinha vendido sozinho este valor. Em poucos meses, ele elevou significativamente o patamar de venda da loja. A empresa o chamou para inaugurar outras lojas. Porém, depois de algum tempo, a empresa mudou a forma de pagar comissão, o que veio a diminuir o salário dos vendedores. Implantaram uma média grupal que passou a diminuir seus ganhos "não é salário individual é salário amarrado". Sofreu uma inversão, pois passou a ganhar menos com os anos de casa. Se no passado chegou a ganhar mais de quatro mil reais, agora ganhava por volta de dois mil. Comentou que a empresa chegou a mudar a política de salário mais de uma vez no mês. Essas mudanças constantes fizeram com que ele não conseguisse vender mais como antes: "Fiquei na lista de corte". Seu trabalho consistia em arrumar o setor, empurrar móveis e fazer esforços físicos. Desenvolveu hérnia de disco, mas os peritos da Previdência Social não caracterizaram como doença profissional, porque ele era registrado como vendedor - os peritos desconhecem a rotina dos vendedores e não estabelecem o nexo causal. Sentia-se injustiçado, apresentando grande desesperança, pensamentos de tirar a própria vida, sensação de fracasso e extrema irritabilidade.

Marta: embora fosse contratada como atendente no restaurante, além de pegar os pedidos e entregar os pratos, ela tinha que fazer o cliente consumir pratos mais caros; também revezava com a atividade de preparo dos pratos na cozinha. Relatou ambiente de muita cobrança e sentia-se mais repreendida que os outros funcionários (provável assédio moral). Conversou com o chefe e melhorou este problema. O ritmo era acelerado, não tinha tempo para comer, disse: "Chegava em casa elétrica".

Seus sintomas começaram após oito meses de trabalho: irritação, choro frequente, agitação, sono alterado (não conseguia dormir ou pegava no sono às 4 ou 5 horas da manhã). Passou a ter alucinações auditivas, ouvia chamarem por ela. As alucinações tinham cessado após o afastamento da empresa. Porém, ocorreu que, depois de alguns meses, teve alta do benefício concedido pela Previdência Social e, retornando a exercer suas funções 
no trabalho, as alucinações voltaram. Queixou-se, além da pressão da chefia, da pressão dos clientes: "O cliente sempre tem razão. Quando reclamava, eu só chorava”.

A empresa tinha uma meta geral dividida pelo grupo e havia premiações quando atingiam a meta (um bônus). O melhor do mês em atendimento ao público ganhava um presente, tendo-o conseguido uma vez. Se conseguisse quatro vezes ganharia um prêmio em dinheiro.

O sofrimento de Marta era intenso. Parecia sempre desorientada e aflita. Tentava trabalhar e não conseguia.

Sueli: relatou que os primeiros sintomas foram desmotivação, irritabilidade com clientes e colegas. Por volta de 2006 - após 18 anos de trabalho na empresa - passou a ficar sem vontade para nada, pedia forças quando levantava para ir trabalhar. Conseguiu vinte dias de férias em janeiro de 2007 e já não conseguiu sair do quarto, nem ver TV, porque aparecia a propaganda da loja na qual trabalhava. Às vésperas de retornar ao trabalho, relatou: "Peguei o meu uniforme e piquei todo com a tesoura". Foi ao médico porque achou que estava ficando louca. Foi afastada e até o momento do atendimento não conseguia ir à loja, nem ao comércio, nem andar sozinha, não suportava barulho. Quando indagada sobre os fatores de adoecimento, disse: "É uma tortura, porque, por mais que se faça, nunca está bom”:

Tenho pesadelos com a empresa. Já sonhei que me falam que tenho que ficar num lugar e não sair. Já sonhei que estava morta no caixão e todos da loja iam me ver e diziam: 'Olha, coitada, se doou tanto e como ela acabou!'. Sonho que perdi o meu armário e não tenho mais onde por minhas coisas.

Sempre vendeu bem, cumpria as cotas estabelecidas, apesar da ameaça de demissão caso não atingisse a meta por três meses consecutivos. A empresa fazia, pela manhã, um teatro de vendas para melhorar o desempenho dos vendedores: "Eu não suportava aquilo [...] porque eu tinha que participar daquilo se eu fechava as cotas? [chorou]". "Se me falarem que tem cinco ou vinte mil reais dentro da loja pra eu pegar, não entro lá, não passo nem em frente".

Sueli contou que não faltava ao trabalho mesmo que estivesse doente, não podia levar as filhas ao médico, porque, se faltasse, tinha que recuperar o que não vendeu naquele dia. Observou com tristeza que, em todas as fotos de aniversário da família, ela aparecia com o uniforme da empresa, porque saia do trabalho tarde e se dirigia para as festas. Não tinha vida pessoal ou familiar, no dia da folga só queria dormir. Chorou e se culpou por ter tratado mal a mãe que sempre cuidou das filhas e disse: "Eu tinha paciência com os clientes e me segurava, mas chegando em casa descarregava na minha mãe que fazia tudo por mim [chorou]”.

Contou que recebeu viagens como premiação pelas vendas, mas preferia não ter ganhado nenhuma delas. A sensação que tinha era de uma viagem relâmpago: "Já passou, tenho que voltar". Relatou que uma mudança na direção da empresa modificou a maneira de tratar o funcionário:
Para o Sr. [antigo diretor da empresa], você tinha valor, sabia o nosso nome. Agora parece que querem se ver livre dos velhos [de empresa] porque os velhos sabem como era [...] Os mais antigos eram mais valorizados e isso ajudava a vestir a camisa.

Vitória: Sueli trouxe a Vitória, que estava afastada por transtorno emocional e também apresentava afecções do sistema musculoesquelético e fibromialgia. Ela relatou que seu problema emocional ocorreu após aumento de pressão e ameaça de demissão por ocasião de um evento grandioso da empresa no final do ano. Saiu deste evento devendo para a empresa porque as vendas foram inferiores ao ano anterior e havia recebido um vale antes de se realizarem. Começou a apresentar dores no corpo e sono excessivo. Disse que sua feição mudou, ficou com o "olho morto" até que, em 2003, teve um surto na loja, descrito como uma sensação de que ia morrer, com falta de ar, tudo rodando, mãos geladas, taquicardia e desequilíbrio ao andar. Pensava durante a crise em como iria criar os filhos. Foi levada ao hospital. Na recepção, antes de ser atendida, deparou-se com um senhor lendo o jornal com a propaganda da rede de lojas na qual trabalhava. Tomada pelo medo, virou-se de costas para o homem. Chorava e sentia medo.

Descreveu a sua atividade profissional desde como fazia a abordagem ao cliente e toda a cortesia necessária, destacando que o cliente, às vezes, é um olheiro (pessoa contratada pela empresa fazendo o papel de cliente para avaliar a qualidade do atendimento). Relatou que, além da pressão pelo cumprimento das cotas de vendas, existia a cota de vendas de garantia do produto e seguro de vida. Comentou que, no início, essa garantia era explicada ao cliente e este escolhia se compraria ou não. Porém, devido às reclamações e às tensões que isso gerou, os vendedores receberam a ordem de embutir a garantia na venda. Como a clientela da loja é constituída majoritariamente por classes menos favorecidas economicamente e com menor nível de escolaridade, a ordem era omitir; se o cliente fosse uma pessoa de nível de escolaridade maior, então se procedia às informações adequadas. Relatou que o gerente passava pelos vendedores e batia nas costas dizendo: "Não esquece o embutex" ou usava a palavra "entubar"- gírias usadas para embutir as garantias. Vitória começou a chorar copiosamente, lembrando que fez isso com uma senhora cega que foi comprar uma TV para os netos. A senhora pediu a prestação mais barata. Vitória fez o cálculo da TV acrescido da garantia e colheu as impressões digitais no contrato; não se perdoava por isso. Comentou com outra vendedora, evangélica, se aquilo não era difícil para ela e esta lhe respondeu: "Estou fazendo o que me mandam". Quando foi sinalizado durante o atendimento psicológico que isto poderia ter sido um dos fatores de adoecimento, ela se surpreendeu e concordou, manifestou um insight sobre o que lhe acontecera. Acrescentou mais adiante que aquela vendedora evangélica que lhe pareceu insensível, tempos depois, caiu em depressão, "porque que ninguém aguenta isso". 
Vitória era muito identificada com a profissão e, quando indagada sobre o que pensava sobre o seu trabalho e porque escolheu a função, ela respondeu:

Quando uma pessoa entrava na loja, eu sentia como se eu realizasse sonhos, porque eram pessoas humildes e me tratavam como se eu fosse importante. Eu fazia de tudo para realizar aquele sonho.

Na sessão seguinte, Vitória chegou com a xerox de uma circular do gerente datada de 29 de março de 2006, na qual se lia:

\section{ATENÇÃO}

Devido ao fechamento de cota, NÃO ESTAREMOS ACEITANDO NENHUMA VENDA SEM SEGURO.

Lembrando que existe uma cota diária para cada vendedor, e estamos sendo acompanhados pela regional. Portanto vamos fazer a nossa parte. Sem mais, Gerência [e no de identificação]. [grifo da empresa]

Esta circular estava assinada por todos os vendedores com o objetivo de comprovar ciência do conteúdo. No dia seguinte à assinatura desta circular, ela passou mal e foi afastada do trabalho. No final da sessão, contou um sonho e descreveu a cena onírica: Ela está atendendo o cliente e faz a venda, mas, quando vai fechar a venda no computador, sempre acontece alguma coisa e não consegue operar o computador, não sabe a senha, alguém a aconselha a ir embora e ela não fica na loja. Pedi para que fizesse associações com sua situação e ela disse:

Eu gosto de atender o cliente, fazer a venda, mas não consigo trabalhar com o sistema [...] é como se eu pudesse ser útil em outra coisa, mas naquele sistema não.

Marina: Veio encaminhada por Vitória que, após uma visita, ficou muito preocupada com o estado emocional da colega de trabalho já afastada das funções. Marina se apresentou muito angustiada, o seu relato era interrompido pelo choro várias vezes. Relatou que, além da pressão por vendas, foi humilhada porque trabalhava no setor de venda de celular quando houve um roubo à noite. O fato gerou pressão sobre os vendedores, ou seja: aumento de controle, contagem com acompanhamento do repositor e do gerente. Passou por uma situação degradante e humilhante na época, quando foi fazer contagem dos celulares no estoque (local de aproximadamente três metros quadrados) e o segurança que a acompanhava precisou sair e a deixou trancada dizendo que logo voltava. Marina estava grávida. Terminou o trabalho e o segurança não voltou, bateu insistentemente na porta e não vinha ninguém. Além do mais, não havia janela na sala. O socorro veio, porém o tempo de espera lhe gerou grande trauma. Sofreu discriminação racial por parte de uma colega do setor motivada pela competição por vendas. Chorou ao contar e acrescentou que um cliente testemunhou o fato e se ofereceu para ajudá-la.

Contou que no evento de fim de ano (próximo ao Natal), em que a empresa costumava montar uma loja es- pecial, ela retornava do trabalho às duas da madrugada e acordava às cinco horas porque morava em outro município. Emagreceu cinco quilos em um mês porque não havia tempo para almoçar e às vezes nem para jantar.

Durante o relato suspirou, começou a chorar e disse:

A gente era obrigada a roubar o cliente e por o dedo da pessoa [para analfabetos]. Se a pessoa perguntava se estava pagando por isso [garantia], eu mentia [chorou]. Tinha clientes que voltavam para comprar comigo porque confiavam em mim [chorou] eu sentia que estava fazendo tudo errado, tudo diferente do que minha mãe me ensinou [chorou].

Contou que a venda cujo seguro e garantia não estivessem embutidos simplesmente não era considerada.

Essa vendedora foi afastada em um dia que estava decidida a se jogar do décimo segundo andar da loja na qual trabalhava, local em que, segundo tinha sido informada, outro vendedor cometera suicídio tempos antes. Apesar da medicação, Marina apresentava-se muito fragilizada. Tentou retornar ao trabalho, mas não conseguiu ficar. Os seus sintomas apareceram após quatro anos de exercício da função nesta loja. Já tinha sido vendedora antes e contou com alegria os bons momentos que teve como vendedora, o quanto se destacou na empresa anterior e mesmo na atual empresa: "Antes eu não trabalhava como escrava igual na [nome da empresa atual]”.

Raquel: Chegou ao Cerest encaminhada pela psiquiatra que a acompanhava desde o início do afastamento de suas funções. Queixava-se de pressão por vendas, ameaça de desemprego, insistência nas vendas de seguro e garantia embutidas, sem consentimento do comprador. Os sintomas começaram no final de 2007 - após três anos na empresa - com pressão na cabeça, falta de ar, dor na coluna. Passou a ficar ríspida, sem paciência com colegas de trabalho e começou a ter que se controlar muito para não perder a calma com os clientes: "Me virava nos 30". Em casa não tinha vontade de conversar com o marido, às vezes nem jantava. "Eu não conseguia me desligar do trabalho". Chegava no dia seguinte à empresa e dizia: "Parece que passei a noite nesta loja”.

A saída do gerente influenciou muito o seu estado emocional, porque ela se sentia protegida por ele (ressalvou que não era só ela que sentia isso), uma vez que ele era justo e "conhecia cada um". Com a mudança de gerência, quem não atingia a meta de seguros tinha o nome estampado próximo ao relógio de ponto. Relatou ser vendedora desde os 13 anos e gostar do que fazia. Entrou na empresa mais recentemente e não conheceu o antigo diretor, ouviu dizer que ele era bom. Comentou:

Hoje os colaboradores não têm valor, não sou eu que digo, são os antigos. Atualmente, por exemplo, se abrir minha tela e não tiver um atraso não significa nada. Antes tinha prêmio. Hoje querem quantidade sem qualidade. Hoje colocam jovem que não têm tanto compromisso. 
Era incapaz de andar sozinha pelas ruas, teve uma crise ao sair do cabeleireiro, não conseguia raciocinar, ficou perdida. Apresentava aversão à propaganda da empresa na TV, não assistia mais à parte de propagandas e não ia ao local de trabalho.

É importante observar que nos oito casos relatados não havia evidência de qualquer problema da vida familiar ou pessoal que concorresse para o desencadeamento dos sintomas apresentados. Valéria e Vitória tinham histórico de separação conjugal antiga - cinco e dez anos antes, respectivamente - mas estavam bem adaptadas. Os demais relataram boa convivência conjugal e familiar, sem outros problemas ou episódios próximos ao aparecimento dos sintomas, o que evidencia a determinante influência dos aspectos relacionados ao trabalho no aparecimento de problemas de saúde física e emocional na amostra aqui selecionada. Obviamente que para fazer a relação dos transtornos mentais com o trabalho não é exigida a inexistência de qualquer outro problema pessoal ou familiar concomitante, mas sim a análise da relevância da influência do ambiente de trabalho num determinado quadro de adoecimento mental.

Aline e Vitória, após acompanhamento psicológico individual e grupal, conseguiram retornar ao trabalho, superando o medo que as impedia de sequer passar perto da empresa. Porém, o equilíbrio emocional não se manteve por muito tempo e Aline, embora continuasse trabalhando, solicitou retorno ao grupo de psicoterapia. Vitória trabalhou alguns meses e foi afastada novamente. Raquel e Valéria, após aproximadamente doze sessões de psicoterapia, voltaram a sair sozinhas pelas ruas, resgatando a autonomia. Sonia e Marta não conseguiram aderir ao acompanhamento psicológico. Lucas passou a brigar judicialmente pelos seus direitos, aumentando sua esperança. Marina passou por poucas entrevistas e foi encaminhada para um Cerest da Capital de São Paulo, porque morava muito longe de Diadema.

\section{Discussão}

Partiremos dos denominadores comuns presentes nos relatos. O primeiro aspecto a ser destacado é que todos os trabalhadores que chegam ao Cerest com transtornos emocionais relacionados à atividade laboral têm aversão ao local de trabalho. Embora este fato não tenha sido citado em todos os relatos acima (apenas naqueles que não conseguiam nem ver a propaganda na TV ou no jornal impresso), esta informação apareceu espontaneamente durante a entrevista. A aversão perdura meses a fio e o tempo para conseguir dirigir-se ao local de trabalho é variável. No caso de Aline, estendeu-se por mais de doze meses após o início da psicoterapia e, mesmo assim, ela apresentou intensos tremores e sudorese quando adentrou a loja, em seu retorno. Estamos falando de um ambiente:
- Atemorizante: ameaças de demissões, metas difíceis de alcançar, "olheiro" (pessoa contratada disfarçada de cliente) para avaliar o atendimento ao cliente;

- Massificante: mesmo atingindo a cota, é necessário participar do teatro de vendas, não importa se faltou muito ou pouco para alcançar a meta; não há singularização. A saída do gerente citada por Raquel a impactou porque ele conhecia cada um, segundo ela. Foi lembrado que o antigo diretor de uma das empresas chamava os funcionários pelo nome e, depois, a relação com os funcionários mudou.

- Culpabilizante: responsabilidade sobre o processo de vendas; o cliente sempre tem razão;

- Competitivo: colegas disputando os clientes; comparações e nomes estampados quando alguém fracassava.

- Verticalizado: ordens vêm da central, nem os gerentes opinam, com pouco ou nenhum espaço para a criatividade;

- Maçante: com muita repetição, lembrando constantemente a meta a ser alcançada; aparelho de som com volume alto para atrair clientes constantemente; teatro de vendas todos os dias; inclusão da propaganda na TV (o que parece reproduzir em parte o clima organizacional citado pelos vendedores);

Vemos que muitos são os fatores que se combinam para criar uma atmosfera facilitadora ao adoecimento. Vários destes trabalhadores, no decorrer da entrevista, eram capazes de fazer comparações com antigos ambientes de trabalho que eram agradáveis ou calmos e tranquilos. Porém, estes depoimentos revelam a todo o momento a intranquilidade do local de trabalho e a transferência deste estado para o ambiente familiar: não conseguiam se desligar, "24 horas no ar". Duas vendedoras relataram sonhos ou pesadelos e uma apenas mencionou que sonhava com o trabalho. As duas trabalhadoras de restaurante apresentaram em comum um estado "elétrico", que muito nos lembra o Charles Chaplin em "Tempos Modernos”, quando saía pelas ruas apertando tudo o que se parecia com os parafusos apertados na fábrica. Então, chegando ao lar, não conseguiam parar de trabalhar, não relaxavam, não dormiam. As duas também apresentavam alucinações no local de trabalho, fato curioso e que mereceria mais acurada investigação e comparação com profissionais de outros restaurantes de grande movimento - ouviam vozes que lhes chamavam. Suponho que eram chamadas muitas vezes durante o expediente. Aline disse que pegou trauma do lugar. A palavra "trauma” em grego quer dizer "ferida" (ZIMERMAN, 2005) e parece que os vendedores falam de um lugar que lhes machuca e faz doer internamente. Geralmente, estes trabalhadores com trauma do ambiente de trabalho desenvolvem um quadro emocional compatível com o transtorno de estresse pós-traumático [CID-10 F-43.1], ou seja: repetidas revivescências do trauma sob 
a forma de memórias intrusivas (flashbacks), sonhos ou pesadelos, embotamento emocional, afastamento de outras pessoas, anedonia, evitação de atividades e situações recordativas do trauma, estado de hipervigilância, insônia (ORGANIZAÇÃO MUNDIAL DA SAÚDE, 1993).

A despersonalização, ou seja, o endurecimento emocional - expresso na atividade do comércio como falta de atenção e cortesia, impaciência para esclarecer o cliente durante a venda, distanciamento afetivo - aparece claramente no relato de Aline. Raquel dá indícios de que esteve prestes a desenvolver a despersonalização, pois declarou que se controlava muito para não perder a paciência com os clientes. Sueli declarou, durante as entrevistas, que muitas vezes não conseguia concluir uma venda porque perdia a paciência com o cliente e passava para outro vendedor. Lucas também citou nervosismo com os clientes pouco antes de se afastar do trabalho, quando percebia que a compra não seria consumada. A exaustão emocional - não ter mais o que dar de si - aparece nos relatos de que não conseguiam dar atenção aos familiares. Sueli disse que pedia forças para enfrentar mais um dia de trabalho. Essa sensação de que eram sugados fica bem evidente em todos os relatos e Marina falou também da exaustão física - sem comer, sem dormir. Aline falou de ficar o dia todo em pé.

Valéria, Sueli e Raquel compareciam ao Cerest Diadema acompanhadas de familiares, pois não conseguiam se locomover sozinhas. Inferimos que a desorientação aparece como uma das consequências desta organização do trabalho. Uma desorientação interna, porque nunca se sabe como agradar, se conseguirá alcançar a meta, se manterá o emprego, se será percebido pela empresa, se dará conta da tarefa. A carga psíquica também é sentida agudamente quando se queixam dos códigos e da atenção exigida. São tantas expectativas para atender, tantas tensões, as quais transbordam para o externo em forma de desorientação espacial: “Onde estou? Para onde vou?”. Perguntas que parecem oriundas de uma outra pergunta: “Quem sou eu?”. Há uma perda de referenciais, o que sugere o aniquilamento de uma identidade. Recentemente foi noticiado um dossiê contando os suicídios ocorridos na France Télécom (MERLO, 2009), onde um dos suicidas escreveu em sua carta de despedida: "Aquilo desorganizou-me totalmente e perturbou-me [...]". As queixas dos funcionários da France Télécom giravam em torno da "urgência permanente", da "sobrecarga de trabalho", da "gestão terror" entre outras, todas atinentes à organização do trabalho. Muito semelhante à nossa realidade, pois a globalização também universaliza o sofrimento.

O sentimento de inutilidade e ausência de saídas parece se expressar na desesperança de Lucas, no sonho macabro de Sueli - estava num caixão - e na idéia de suicídio de Marina. Winnicott (1971, p. 95) afirma: "A submissão traz consigo um sentido de inutilidade e está associada à ideia de que nada importa e de que não vale a pena viver a vida”. O clima presente nas entrevistas é de desamparo, de horror, de ressentimento profundo. São pessoas atormentadas, que, mesmo afastadas do ambiente de trabalho, carregam a tortura dentro de si mesmas. O sonho de
Vitória é muito interessante no que tange à organização do trabalho, porque a tarefa lhe parecia muito agradável; o que se tornava insuportável era o "sistema". No caso desta trabalhadora, como também do Lucas, havia uma grande identificação com a profissão. Vitória se dizia uma "realizadora de sonhos", sentia-se importante ao poder viabilizar os sonhos dos compradores. Disse, inclusive na entrevista, que havia uma margem de desconto que ela poderia fazer. Enfim, ela via uma causa nobre associada ao seu fazer cotidiano, relatou isto com brilho nos olhos. Este é um fator muito saudável presente na tarefa:

O que nos caracteriza não é a nossa capacidade de produzir mercadorias, mas sim a nossa possibilidade de emprestar, criar e revelar sentidos por meio do nosso agir, de nosso trabalho. A vocação humana é fundamentalmente poético-religiosa. Quero dizer com isso que é inerente ao homem a capacidade de encantar-se com o cotidiano e enxergar nele o eterno. (SAFRA, 2006, p. 62)

É lamentável que a organização do trabalho prive os trabalhadores do prazer alcançado com a realização da atividade, pois há uma sensação perene de que não se alcançou o desejável. Há uma desconfiança constante, visto ser preciso lembrá-los a todo instante que precisam vender, como também contratar "olheiros". O modo de cobrar a tarefa e avaliá-la parece provocar uma infantilização concomitante, porque é como se não soubessem o que precisam fazer. Daí uma das causas da revolta de Sueli com o teatro de vendas. A presença do "olheiro" não é um relato oriundo de mania de perseguição dos vendedores. $\mathrm{O}$ fato foi confirmado em visita à empresa, pelo Diretor de Recursos Humanos, o qual disse que outrora usaram deste expediente (equipe de técnicos dos Cerests da região do grande $\mathrm{ABC}$ visitaram a empresa algumas vezes). Esta característica de cobrança exagerada aparece nas quatro empresas em questão. Inclusive, parece gerar o presenteísmo que transparece no relato de Sueli, a qual declarou não faltar ao trabalho nem para levar as filhas ao médico, senão o cumprimento das metas não se concretizava. E muitos já relataram que compareciam ao trabalho doentes, com dores e até com atestado médico em mãos.

O reconhecimento da pessoa é falseado e por isso Sueli disse que preferia não ter sido premiada com as viagens. A impressão que se tem é que os prêmios lembram o baile da Cinderela, pois o sonho acaba logo e tudo volta a ser como antes. Os brindes e as viagens não são experimentados como conquista de prestígio, de afeto e estima. O efeito do descanso também é passageiro porque a rotina das empresas suga a energia rapidamente. Sueli chegou a citar que vendedores com menos tempo de serviço que ela foram promovidos. Há o sentimento de injustiça. Ela avalia que as promoções se dão pela bajulação à chefia e não por aquilo que se faz. Percebe-se desta forma a distorção que ocorre com tais premiações. Este é um dos elementos que predispõem ao transtorno emocional relacionado ao trabalho, uma vez que, segundo Zimerman (2010), todos necessitam vitalmente do reconhecimento das pessoas para a manutenção da autoestima. E afirma: 
Portanto, a importância mais significativa do termo "reconhecimento" alude a uma necessidade crucial de todo ser humano, em qualquer idade, circunstância, cultura, época ou geografia, de desejar sentir-se reconhecido e valorizado pelos demais e sentir que realmente existe como individualidade. (ZIMERMAN, 2010, p. 212)

Ter uma individualidade e vê-la respeitada é fator que favorece a manutenção da saúde mental. Percebemos a lacuna da organização do trabalho neste ponto com o fato agravante de gerar conflitos a esta individualidade quando uma norma antiética é implantada. Se observarmos as quatro vendedoras da mesma loja (Sueli, Vitória, Marina e Raquel), que têm tempos de trabalho na empresa diferentes, parece que o adoecimento é mais recente e coincide com a mudança de direção da empresa e/ou com a implantação desta venda atrelada de garantia e seguro, sendo que a direção mudou por volta de 2003 e a venda de seguro é posterior. A circular de 2006 trazida por Vitória marca o momento da exigência de vendas com seguro sob a ameaça de não serem computadas aquelas vendas.

O conflito ético corrói o indivíduo que necessita do trabalho e não desejaria cumpri-lo na íntegra, como a empresa exige. Sente-se um enganador. Caso engane a empresa, sofre ameaça e, se engana o consumidor, sente-se vil. Marina expressa a vergonha de si mesma, a perda de identidade com a sua raiz - representada pelos ensinamentos da mãe. É como se não fosse mais aceita pela própria mãe e a repercussão emocional é profunda. Seligmann-Silva (2003) pensa que, se cedem às pressões deformadoras ou até violentadoras quando diante de ameaças à sobrevivência - empresas ou pessoas -, tendem à degradação, deixando ruir os valores que constituíam os alicerces do sentido de suas existências.

A ideia de suicídio de Marina parece ser decorrente de uma somatória de pressões e dissabores no trabalho. Porém, há a hipótese de ter sido muito determinada pelo conflito ético, porque boa parte dos suicidas não deseja por fim as suas vidas, mas pretendem dar um sinal de alarme, como um grito de socorro, ou ainda para castigar, culpar ou sensibilizar alguém (ZIMERMAN, 2005). Isso nos leva a pensar que o suicídio seria cometido no local do trabalho, funcionando como uma comunicação, um grito que precisa ser escutado naquele local.

Outro aspecto a observar é o conflito interno de Marina com os ensinamentos da mãe e os comentários dos demais vendedores sobre o prejuízo da relação familiar - convívio familiar, afeto, presença -, os quais provam que não há como separar o pessoal e o familiar do ambiente de trabalho. Esta cisão de colocar os pés no trabalho e esquecer-se de casa não é natural para o ser humano que carrega, a um só tempo, o ontem (herança genética, lembrança, valores), o hoje e o seu anseio de futuro, o devir. O conflito família versus trabalho está presente continuamente e, por isso, a organização do trabalho tem que prever os limites necessários para que não se instaure a desumanização. $\mathrm{O}$ desrespeito a estes limites leva à síndrome do esgotamento profissional caracterizada pela exaustão emocional - um esvaziamento de si, não ter mais o que dar afetivamente; pela despersonalização - endurecimento emocional, insensibilidade com as pessoas atendidas, "coisificação" da relação; e pela falta de envolvimento pessoal no trabalho - sentimentos de diminuição de competência, afetando a habilidade para realizar o trabalho e o atendimento ou contato com as pessoas usuárias do serviço (CODO; VASQUES-MENEZES, 2000). Sintomas esses passíveis de serem identificados na amostra apresentada.

Lucas e Marina relatam ter trabalhado no comércio desde o início da carreira profissional, contam trajetória de sucesso e boa adaptação. Ambos têm identificação com a profissão, assim como Vitória e Sueli. É possível perceber o quanto a organização do trabalho distorceu a relação saudável entre profissional e empresa. É indispensável criar um ambiente propício à saúde e ao desenvolvimento humano, pois a atmosfera criada tem interferência direta na saúde física e emocional.

Estudos sobre a abordagem da psiconeuroimunologia mostram que uma intervenção de enfermagem e relaxamento eleva o grau de defesas pró-saúde, conforme o estudo de Amorim (1999, apud VIEIRA DA SILVA, 2001). A pesquisadora trabalhou com 60 mulheres com câncer de mama buscando avaliar os efeitos da intervenção no sistema imunológico destas, sem diagnóstico de metástase à distância. As coletas de sangue no grupo controle revelaram que, após a intervenção enfermagem-relaxamento, houve um aumento significativo das células que possuem atividade antitumoral (células natural killer - NK), podendo ser comparadas à atividade de mulheres sadias. O resultado evidencia como somos permeáveis a todas as experiências que nos cercam, com a possibilidade de grandes mutações dos aspectos físicos e emocionais. Neste sentido, mas sem esta pretensão, oferecemos no Cerest grupos para os trabalhadores adoecidos como uma forma de acolhimento e minimização das angústias. Os grupos de orientação que recebem os usuários pela primeira vez no serviço, bem como os grupos psicoterápicos para trabalhadores com sofrimento mental, funcionam como uma forma de berçar, segurar e sustentar pessoas atravessadas pelo despedaçamento emocional. Vieira Neto e Vieira (2005) explicam que as pessoas traumatizadas agem de modo semelhante a uma criança, que, após uma queda, corre para os braços da mãe. $\mathrm{O}$ abraço da mãe não tem o poder de cicatrizar a ferida, mas tem a capacidade de mostrar à criança que está amparada e que sua dor é superável.

\section{Comentários finais}

Este breve relato da vivência dos trabalhadores permitiu uma aproximação em relação à importância que desempenha o ambiente de trabalho e às proporções do sofrimento que esse ambiente pode causar. O esfacelamento do ser se dá de maneira lenta, mas contínua e progressiva, sendo que o tempo e a intensidade da destruição são variáveis. Por outro lado, pode-se perceber o trabalho como veículo de construção de autoestima, realização e um espaço para o desenvolvimento do ser, quando bem conduzido. $\mathrm{O}$ ambiente de trabalho sau- 
dável permitiria experimentar a atividade laboral como correlata do brincar infantil, tornando-se um espaço para o acontecer humano na sua plenitude. Aponta para o caminho da prevenção, pois a organização do trabalho pode ser pensada de maneira que os trabalhadores se sintam singulares, exerçam sua criatividade, encontrem orgulho no serviço que prestam, sejam reconhecidos nas suas habilidades e responsabilidades, possam ter autonomia - como, por exemplo, poder, no mínimo, escolher sobre o embutir produtos ou criar outras estratégias de convencimento -, possam escolher se querem trabalhar até mais tarde ou não. O trabalho precisa preencher uma parte importante do dia, da vida, mas não a sua totalidade. Há limite para o exercício da função em favor da permanência da saúde de quem trabalha e da satisfação com o que se faz. A família ocupa um lugar especial na subjetividade de cada um e a organização do trabalho não pode desconsiderar esta dimensão.

A realidade aqui apresentada vale também para outras categorias profissionais, daí o fato de se agregar duas trabalhadoras do ramo de alimentos. Sabemos que os bancários hoje são vendedores, os caixas de farmácia, os frentistas de postos de gasolina, enfim, vários profissionais precisam oferecer produtos aos clientes e fazê-los consumir para obtenção da meta desejável. Com base no material apresentado, torna-se útil incluir a investigação deste aspecto em nossas entrevistas com trabalhadores adoecidos mentalmente para identificar possíveis pontos de tensão relacionados com metas de vendas ou outras de qualquer natureza.

As anamneses ocupacionais devem atentar para a subjetividade dos trabalhadores, tentando captar o sentido de suas funções, se há reconhecimento explícito do seu trabalho, se existem possíveis conflitos éticos ou conflito família versus trabalho.
O afastamento do contexto de trabalho por ocasião do adoecimento cria um vazio existencial. É de vital importância haver um espaço privilegiado - Cerest, Sindicato, Unidades de Saúde - para a elaboração do sofrimento mental causado pelo ambiente de trabalho. Ter um lugar para ser escutado, compreendido, pode ser restaurador, levando o trabalhador a reconstituir sua identidade. Também fornece condições para retornar à atividade laboral, modificado ou mesmo reinventando o seu caminho profissional.

O material apresentado suscita perguntas e pode motivar várias análises e pesquisas na categoria. Podemos, a título de exemplo, pensar sobre as análises periciais na Previdência Social que, por desconhecimento, não consideram os riscos ocupacionais gerados pela organização do trabalho. O perfil profissiográfico previdenciário dos vendedores torna-se falso por não incluir este tipo de risco, bem como a exclusão das atividades reais exercidas pelos vendedores, as quais incluem: uso do computador para levantar preços, ver estoque e digitalizar as vendas; escrever; levantar carga; arrumar o setor fazendo esforço físico, gerando afecções do sistema musculoesquelético. Seriam muito úteis estudos comparativos entre empresas que atuam no ramo de serviços com formas de organização do trabalho diversas e seus consequentes efeitos.

Torna-se primordial a disseminação dos conhecimentos relacionados à saúde mental e trabalho para que trabalhadores e profissionais se apropriem de um saber que pode evitar o aparecimento ou o agravamento de transtornos emocionais. Talvez possamos caracterizar este empenho como uma causa ecológica para evitar a extinção do respeito à dignidade humana nos ambientes de trabalho. Como dizia Guimarães Rosa (2006, p. 311): "Qualquer amor já é um pouquinho de saúde, um descanso na loucura".

\section{Agradecimentos}

A autora expressa gratidão à Professora Doutora Jussára Van de Velde Vieira da Silva e ao Professor Cláudio Manoel Gomes pela leitura atenta e pelas preciosas sugestões.

\section{Referências}

ANTUNES, R. Os sentidos do trabalho: ensaio sobre a afirmação e negação do trabalho. São Paulo: Boitempo, 1999.

CODO, W.; VASQUES-MENEZES. O que é Burnout?. In: CODO, W. et al. (Org.) Educação: carinho e trabalho. Petrópolis: Vozes, 1993. p. 237-254.

FREUD, S. O mal-estar na civilização (1930). In: SALOMÃO, J. Os pensadores. São Paulo: Abril Cultural, 1978. p. 129-194.

MACHADO, R. Em que posso ajudar? Avaliação de sinais de sofrimento psíquicos em vendedores que trabalham no comércio de shopping center da grande
Florianópolis. 2009. 68 f. Trabalho de Conclusão de Curso (Especialização em Psicologia e Trabalho Humano)-Faculdade de Psicologia, Universidade do Sul de Santa Catarina, Palhoça, 2009.

MERLO, A. R. C. Suicídios na France Télécom: as conseqüências nefastas de um modelo de gestão sobre a saúde mental dos trabalhadores. Disponível em: <http://www.liberation.fr>. Acesso em: 1 dez. 2009.

ORGANIZAÇÃO MUNDIAL DE SAÚDE. Classificação de transtornos mentais e de comportamento da CID 10: descrições clínicas e diretrizes diagnósticas. Porto Alegre: Artmed, 1993. 
ROSA, J. G. Grande Sertão: Veredas. Rio de Janeiro: Nova Fronteira, 2006.

SAFRA, G. Desvelando a memória do humano: o brincar, o narrar, o corpo, o sagrado, o silêncio. São Paulo: Sobornost, 2006.

SELIGMAN-SILVA, E. Psicopatologia e saúde mental no trabalho. In: MENDES, R. Patologia do trabalho. 2. ed. São Paulo: Atheneu, 2003.

SIMON, R. Introdução à psicanálise: Melanie Klein. São Paulo: EPU, 1986.

VASQUES-MENEZES, I.; CODO, W.; MEDEIROS, L. O conflito entre o trabalho e a família e o sofrimento psíquico. In: CODO, W. et al. (Org.). Educação: carinho e trabalho. Petrópolis: Vozes, 2000. p. 225-260. .; GAZZOTTI, A. A. Suporte afetivo e o sofrimento psíquico em Burnout. In: CODO, W. et al. (Org.). Educação: carinho e trabalho. Petrópolis: Vozes, 2000.
VIEIRA DA SILVA, J. V. Câncer de mama: expressões da religiosidade e suas repercussões na convivência com a doença num grupo de mulheres mastectomizadas. 2001. 172 f. Tese (Doutorado em Ciências da Religião)-Faculdade de Filosofia e Ciências da Religião, Universidade Metodista de São Paulo, São Bernardo do Campo, 2001.

VIEIRA NETO, O.; VIEIRA, C. M. S. (Org.). Transtorno de estresse pós-traumático: uma neurose de guerra em tempos de paz. São Paulo: Vetor, 2005.

WINNICOTT, D. W. O brincar \& a realidade. Rio de Janeiro: Imago, 1971.

ZIMERMAN, D. E. Psicanálise em perguntas e respostas: verdades, mitos e tabus. Porto Alegre: Artmed, 2005.

. Os quatro vínculos: amor, ódio, conhecimento, reconhecimento na psicanálise e em nossas vidas. Porto Alegre: Artmed, 2010. 